\title{
Structural Investigation and Anti-Stokes Emission of Scandium Oxide Nanocrystals Activated with Trivalent Erbium
}

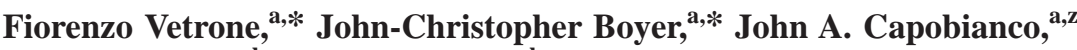 \\ Adolfo Speghini, ${ }^{\text {b }}$ Marco Bettinelli, ${ }^{b}$ Radenka Krsmanovic, ${ }^{\text {c }}$ and Stefano Polizzic \\ ${ }^{a}$ Department of Chemistry and Biochemistry, Concordia University, Montreal, Quebec H4B 1R6, Canada \\ ${ }^{b}$ Dipartimento Scientifico e Tecnologico, Università di Verona, and INSTM, UdR Verona, I-37134 Verona, \\ Italy \\ 'Dipartimento di Chimica Fisica, Università Ca' Foscari, Venezia-Mestre, Italy
}

\begin{abstract}
The structural and emission (Stokes and anti-Stokes) properties of $\mathrm{Sc}_{2} \mathrm{O}_{3}: \mathrm{Er}^{3+}$ nanocrystals doped with $0.1,1$, and 10 mol $\% \mathrm{Er}^{3+}$ were investigated. The nanocrystalline powders were characterized using X-ray scattering as well as transmission and scanning electron microscopy. The samples showed a very porous, open microstructure with the particles having a narrow distribution of sizes $(10-60 \mathrm{~nm})$. Furthermore, the mechanisms responsible for the anti-Stokes emission $\left(\lambda_{\text {exc }}=980 \mathrm{~nm}\right)$ were elucidated. We observed that the processes responsible for populating the green $\left({ }^{2} \mathrm{H}_{11 / 2},{ }^{4} \mathrm{~S}_{3 / 2}\right)$ and red $\left({ }^{4} \mathrm{~F}_{9 / 2}\right)$ emitting states were dependent upon the concentration of the dopant ion. In $0.1 \mathrm{~mol} \%$ nanocrystalline $\mathrm{Sc}_{2} \mathrm{O}_{3}: \mathrm{Er}^{3+}$, upconversion was determined to occur via excited state absorption while in the $10 \mathrm{~mol} \%$ sample, energy transfer upconversion was the dominant mechanism. An enhancement of the red anti-Stokes emission from the ${ }^{4} \mathrm{~F}_{9 / 2} \rightarrow{ }^{4} \mathrm{I}_{15 / 2}$ transition was observed in $\mathrm{Sc}_{2} \mathrm{O}_{3}: \mathrm{Er}^{3+}$ nanocrystals as a function of Er ${ }^{3+}$ concentration. This was the result of two independent processes responsible for directly populating the ${ }^{4} \mathrm{~F}_{9 / 2}$ state and bypassing the green emitting levels $\left({ }^{2} \mathrm{H}_{11 / 2}\right.$ and $\left.{ }^{4} \mathrm{~S}_{3 / 2}\right)$. Furthermore, the red enhancement was found to be more pronounced compared to identically doped $\mathrm{Y}_{2} \mathrm{O}_{3}: \mathrm{Er}^{3+}$ nanocrystals. An explanation for this phenomenon is presented and discussed. (C) 2004 The Electrochemical Society. [DOI: 10.1149/1.1843091] All rights reserved.
\end{abstract}

Manuscript submitted April 9, 2004; revised manuscript received July 1, 2004. Available electronically December $17,2004$.

The advances in nanoscale preparation techniques present an opportunity for the materials researcher to elucidate the properties of known materials synthesized directly in the nano domain without having to undergo the mechanical grinding techniques associated with conventional syntheses. A multitude of synthesis methods exist to prepare luminescent nanocrystals ranging from the very exotic (and expensive) to the very simple, involving only a heat source to initiate a combustion reaction.

In this paper we study the luminescence (anti-Stokes emission, specifically) of scandium oxide $\left(\mathrm{Sc}_{2} \mathrm{O}_{3}\right)$ nanocrystals prepared by such a simple preparation technique, solution combustion synthesis (otherwise known as propellant synthesis). The propellant synthesis involves mixing the metal nitrate starting materials with an organic fuel to propagate the combustion reaction. ${ }^{1,2}$ Large quantities of gases are liberated as by-products of the synthesis reaction, which play a pivotal role by preventing the particle growth. One of the most attractive features of the combustion synthesis is that nanocrystals are produced at relatively low temperatures with reduced processing time. Thus, a high-temperature furnace is not required as the reaction is initiated at temperatures of $500^{\circ} \mathrm{C}$ or less. ${ }^{3}$ In a typical reaction the precursor mixture of distilled water, oxidizer, and fuel decomposes, dehydrates, and ruptures into a flame after approximately $5 \mathrm{~min}$ creating a voluminous foamy powder. The combustion reaction is influenced by a number of parameters such as type of fuel, fuel-to-oxidizer ratio, use of excess oxidizer, ignition temperature, and water content of the precursor mixture. ${ }^{4,5}$

The luminescence of nanoparticles has attracted a great deal of interest. In semiconductor nanocrystals for example, quantum size effects result when the size of the particle approaches the Bohr excitonic radius. ${ }^{6-8}$ This quantum confinement results in an increase in the bandgap that in turn leads to a blue shift in the optical spectrum. ${ }^{9}$ In insulating materials such as $\mathrm{Y}_{2} \mathrm{O}_{3}: \mathrm{Ln}^{3+}$, the bandgaps are very large with the electronic energy levels of the dopant ion residing within the bandgap. Thus quantum confinement is not observed in such materials. ${ }^{10}$ However, due to the large surface area, a number of size effects are observed. Most notably, atmospheric $\mathrm{CO}_{2}$ and $\mathrm{H}_{2} \mathrm{O}$ is adsorbed on the nanoparticle surface, which results in increased vibrational energies and thus, different luminescent behav-

* Electrochemical Society Student Member.

z E-mail: capo@vax2.concordia.ca ior compared to the bulk material. This is especially true in nanocrystalline insulators doped with rare earth ions. For example, the emission of $\mathrm{Y}_{2} \mathrm{O}_{3}: \mathrm{Er}^{3+}$ is much weaker than its microcrystalline counterpart due to the high vibrational energies associated with the adsorbed $\mathrm{CO}_{3}{ }^{2-}\left(1500 \mathrm{~cm}^{-1}\right)$ and $\mathrm{OH}^{-}\left(3350 \mathrm{~cm}^{-1}\right)$ species. ${ }^{11} \mathrm{In}$ fact, as we demonstrate in this paper, these large vibrational energies could lead to different mechanisms, compared to the bulk material, which are responsible for populating the emitting states in the antiStokes spectra.

Scandium oxide is isostructural to cubic $\mathrm{Y}_{2} \mathrm{O}_{3}$ but its lattice constant is smaller (see below). ${ }^{12}$ Moreover, the $\mathrm{Sc}^{3+}$ ion is much smaller than $\mathrm{Y}^{3+}$, which induces a stronger crystal field and a larger Stark splitting of the multiplets. ${ }^{13} \mathrm{Sc}_{2} \mathrm{O}_{3}$ possesses a high refractive index, large bandgap $(5.7 \mathrm{eV})$, and high melting point $(2753 \mathrm{~K})$, which makes it ideally suited for a number of applications. ${ }^{14}$

We present a detailed structural and morphological characterization together with a study of the anti-Stokes emission properties of $\mathrm{Sc}_{2} \mathrm{O}_{3}: \mathrm{Er}^{3+}$ nanocrystals as a function of $\mathrm{Er}^{3+}$ concentration. Furthermore, we investigate the mechanisms, which give rise to the anti-Stokes emission and the radiative and nonradiative pathways that make this process possible.

\section{Experimental}

Scandium oxide $\left(\mathrm{Sc}_{2} \mathrm{O}_{3}\right)$ nanocrystals doped with $0.1,1$, and 10 mol \% of $\mathrm{Er}^{3+}\left(\mathrm{Sc}_{1.998} \mathrm{Er}_{0.002} \mathrm{O}_{3}, \mathrm{Sc}_{1.98} \mathrm{Er}_{0.02} \mathrm{O}_{3}, \mathrm{Sc}_{1.8} \mathrm{Er}_{0.2} \mathrm{O}_{3}\right.$, respectively) were prepared using a solution combustion synthesis procedure (propellant synthesis). ${ }^{1,2}$ The propellant synthesis reaction involved preparing an aqueous solution containing glycine and the metal nitrates, $\mathrm{Sc}\left(\mathrm{NO}_{3}\right)_{3}$ and $\mathrm{Er}\left(\mathrm{NO}_{3}\right)_{3}$. The glycine serves as fuel for the propellant reaction, being oxidized by the nitrate ions, as described in Ref. 2. After the combustion, the powder was fired for $1 \mathrm{~h}$ at $500^{\circ} \mathrm{C}$ in order to decompose the residual nitrate ions. All scandia samples were kept in air without any further precaution.

A Philips X'Pert vertical goniometer with Bragg-Brentano geometry, connected to a highly stabilized generator, was used for X-ray diffraction (XRD) analysis. $\mathrm{Co}-\mathrm{K} \alpha$ (Fe-filtered) radiation, a graphite monochromator on the diffracted beam and a proportional counter with pulse height discriminator, were used. For the determination of the lattice parameters measurements on a $20^{\circ}-100^{\circ}$ range in $2 \theta$ (Bragg angle) were collected with a step size of $0.05^{\circ}$ and $10 \mathrm{~s}$ per point for three runs and then averaged. The cubic unit cell edge values were calculated by using the angular peak position of 22 reflections. In accordance with Wagner, ${ }^{15,16}$ the cell edge value was 


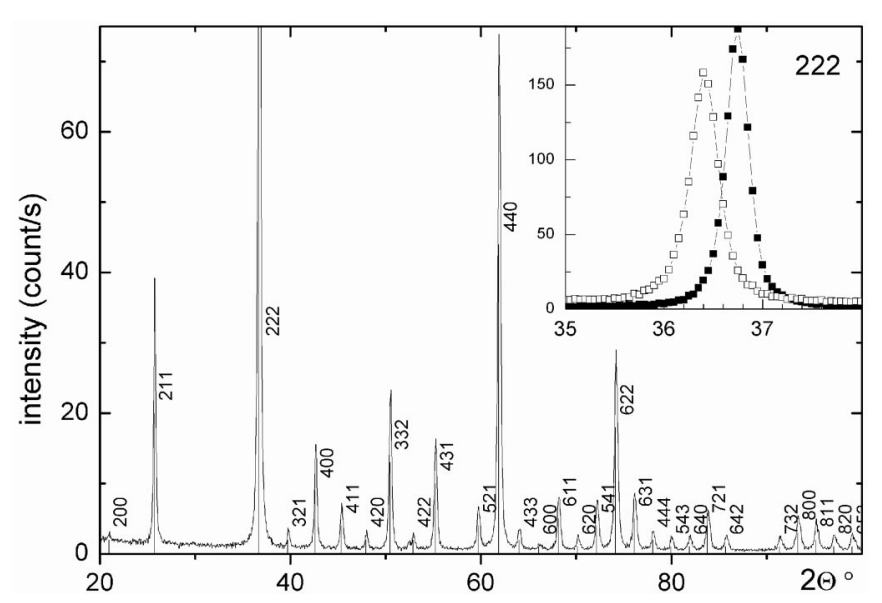

Figure 1. XRD pattern of the nanocrystalline $\mathrm{Sc}_{2} \mathrm{O}_{3}$ sample obtained by propellant synthesis and (inset) of the (222) peaks for the $10 \mathrm{~mol} \% \mathrm{Er}^{3+}$ doped ( $\square$ ) and undoped ( $\square$ ) nanocrystalline $\mathrm{Sc}_{2} \mathrm{O}_{3}$ samples showing the peak shifts and the different profile width. The (222) peak is not shown entirely in the full spectrum (see inset).

extrapolated by applying a weighted least-square linear fit to the cell edge values calculated from the position of each single reflection as a function of $\cos \theta \operatorname{cotg} \theta$. The peak position was obtained using a previously reported best-fitting procedure, ${ }^{17,18}$ where each peak is described by a couple of constrained pseudo-Voigt functions $\left(K_{\alpha_{1}}\right.$ and $K_{\alpha_{2}}$ profiles) and the background by a polynomial function.

The line-broadening analysis was carried out by the WarrenAverbach method, ${ }^{19,20}$ using the $222 / 444$ pair of reflections, for obtaining the volume-weighted average crystallite size, $\langle D\rangle_{\mathrm{v}}$, and the distribution of microstrains $\left\langle\varepsilon^{2}(D)\right\rangle$. The instrumental broadening was previously deconvolved by using Stokes' method, adapted to analytically defined profiles.

Scanning electron microscopy (SEM) images were taken with a Jeol JSM 5600 LV electron microscopy. Samples were coated with an Au thin film, in order to avoid charging effects.

Transmission electron microscopy (TEM) images were taken with a Jeol 3010 , operating at $300 \mathrm{kV}$, equipped with a Gatan slow scan charge-coupled device (CCD) camera (model 794). The powder was dispersed in an isopropyl alcohol solution by a short sonication and a $5 \mu \mathrm{m}$ drop was deposited on a copper grid coated with a carbon holey film.

The visible Stokes emission spectra were obtained by exciting the nanocrystalline material at $488 \mathrm{~nm}$ using a Coherent Sabre Innova, $20 \mathrm{~W}$ argon ion laser. Anti-Stokes emission spectra were obtained with $980 \mathrm{~nm}$ using a Spectra-Physics model 3900 titanium sapphire laser pumped by the $514.5 \mathrm{~nm}$ line of the Coherent Sabre Innova argon ion laser. The visible emissions were collected using a Jarrell-Ash 1 meter Czerny-Turner double monochromator and dispersed with a thermoelectrically cooled Hamamatsu R943-02 photomultiplier tube. A preamplifier, model SR440 Stanford Research Systems, processed the photomultiplier signals and a gated photon counter model SR400 Stanford Research Systems data acquisition system was used as an interface between the computer and the spectroscopic hardware. The signal was recorded under computer control using the Stanford Research Systems SR465 software data acquisition/analyzer system.

The decay curves were obtained by modulating the 488 and 980 $\mathrm{nm}$ excitation lines using an optical chopper (Stanford Research Systems, model SR 540) and were recorded using the above mentioned data acquisition system.

\section{Results and Discussion}

XRD patterns (Fig. 1) indicate that pure scandia $\left(\mathrm{Sc}_{2} \mathrm{O}_{3}\right.$, cubic system; space group Ia3) has been obtained. No other phases or a

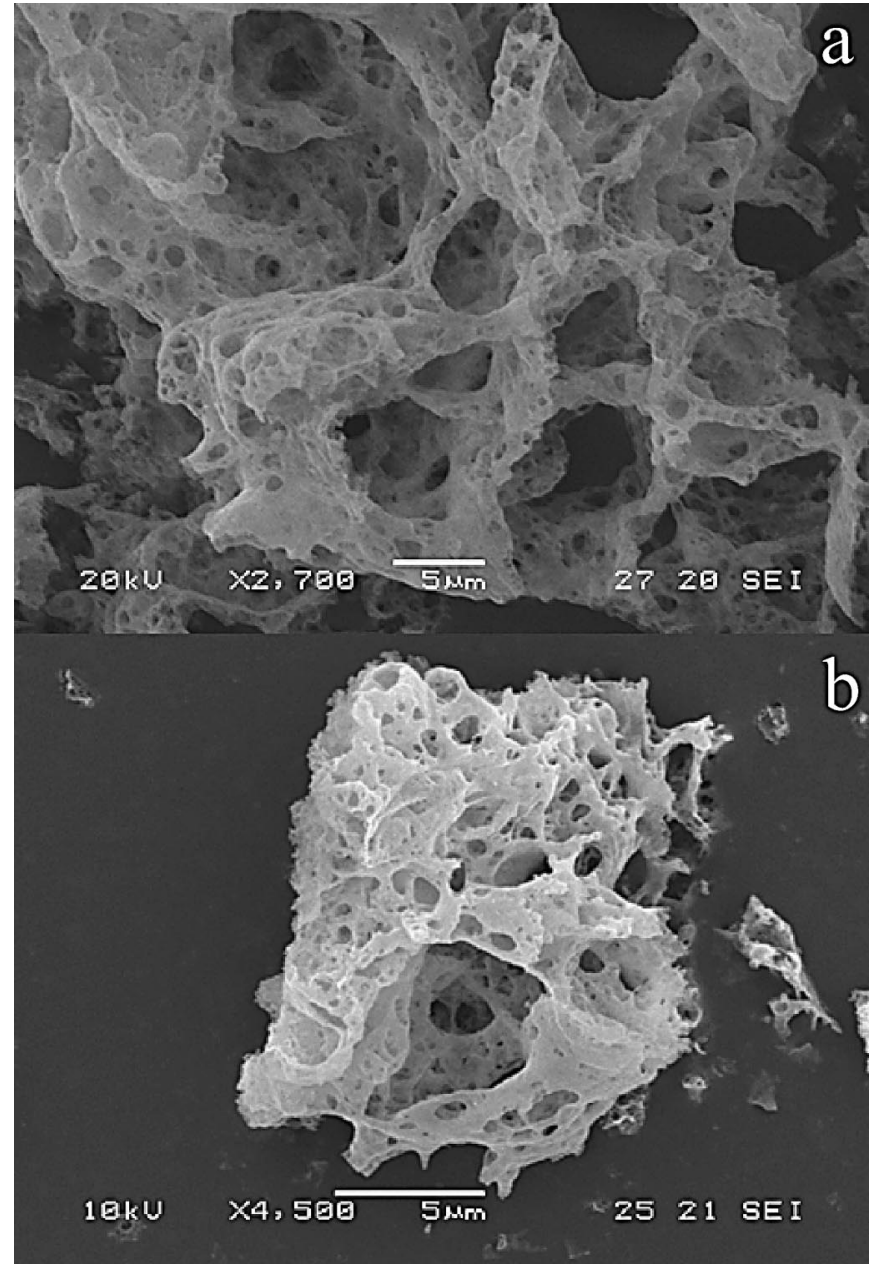

Figure 2. $\mathrm{SEM}$ images of a typical $\mathrm{Sc}_{2} \mathrm{O}_{3}$ sample.

significant amorphous fraction is present in the material. Peak shifts are observed for the $10 \mathrm{~mol} \% \mathrm{Er}^{3+}$ doped sample (see inset of Fig. 1). The unit cell edge value, $a$, obtained for the undoped scandia sample $[9.8378(7) \AA]$ is smaller then the one reported in the literature $^{21}[9.8450(4) \AA]$, whereas a larger value is obtained for the $10 \mathrm{~mol} \% \mathrm{Er}^{3+}$ doped sample [9.9056(5) $\AA$ ], as expected from the larger value of the $\mathrm{Er}^{3+}$ ionic radius with respect to that of the $\mathrm{Sc}^{3+}$ ion. ${ }^{22}$ A quantitative line broadening analysis of the diffraction peaks indicates a crystallite volume averaged dimension of $37 \mathrm{~nm}$ for the undoped sample and $27 \mathrm{~nm}$ for the $10 \mathrm{~mol} \% \mathrm{Er}^{3+}$ doped sample. No significant microstrains have been revealed.

In Fig. 2, typical SEM images of the $\mathrm{Sc}_{2} \mathrm{O}_{3}$ nanocrystals are shown. The morphology is typical for samples prepared by propellant synthesis showing a microscopic open, sponge-like appearance, which is usually related to a fractal structure. ${ }^{23-25}$

In Fig. 3 TEM micrographs of the $\mathrm{Sc}_{2} \mathrm{O}_{3}$ sample are shown at different magnifications together with a selected area diffraction pattern. The sample is composed of interconnected crystalline particles with irregular, sharp-edged shapes and dimensions ranging from 10 to $60 \mathrm{~nm}$ (the larger crystals are not present in this particular image). HRTEM images (Fig. 4) show that these particles, which are the building units of the porous structure, are single crystallites. Some small voids are visible, which are probably generated by gas bubbles during the very rapid combustion process. As already observed for previously studied samples, ${ }^{23-25}$ the presence of such voids tend to yield underestimated values for the sizes obtained by XRD, because of the limiting action of the pores on the coherence for diffraction. 


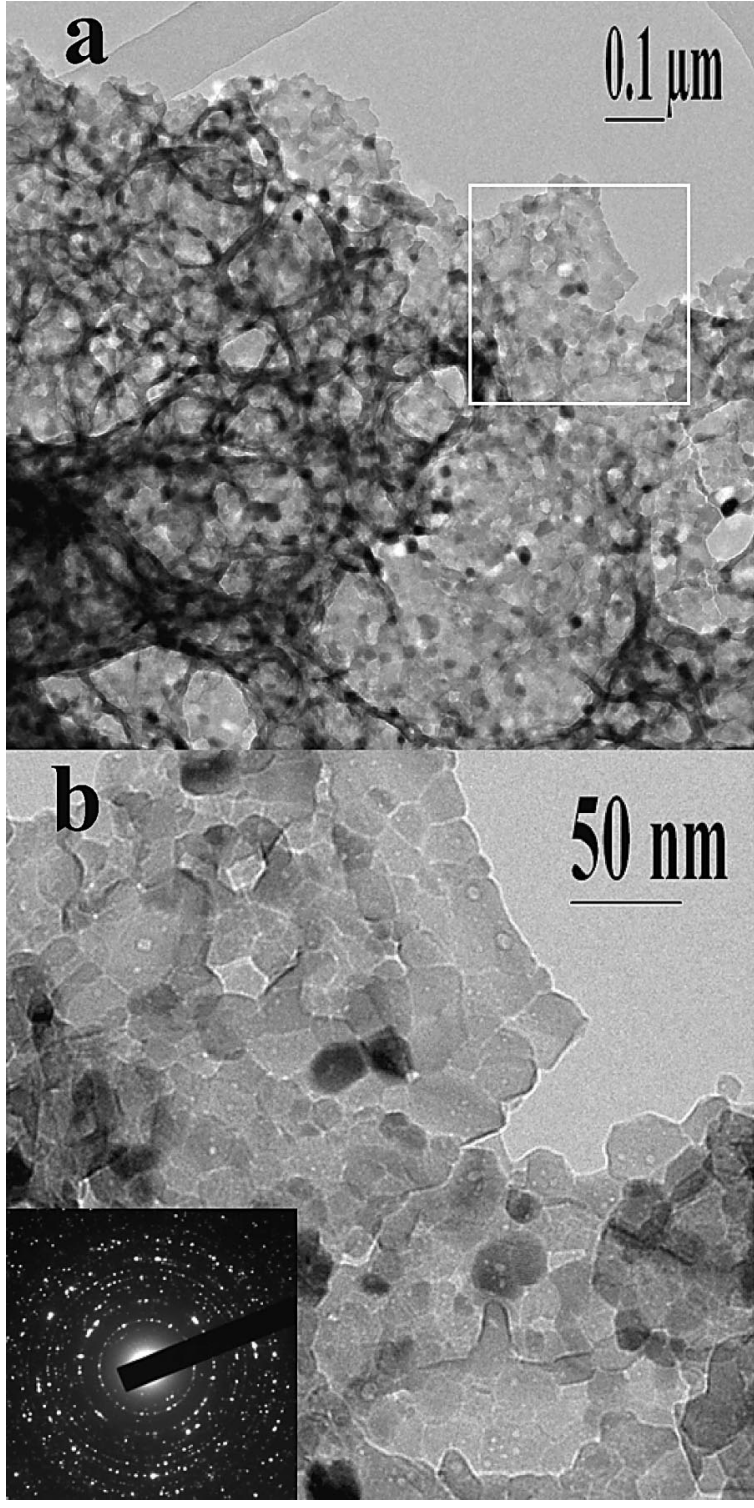

Figure 3. TEM micrographs of a $\mathrm{Sc}_{2} \mathrm{O}_{3}$ sample and a selected diffraction pattern. The white square in (a) shows the region enlarged in (b).

The $\mathrm{Er}^{3+}$ ion replaces the $\mathrm{Sc}^{3+}$ ion in the C-type $\mathrm{Sc}_{2} \mathrm{O}_{3}$ lattice with no charge compensation. C-type $\mathrm{Sc}_{2} \mathrm{O}_{3}$ has a cubic unit cell with two different site symmetries and occupation rates: $C_{3 \mathrm{i}}(1 / 4)$ and $C_{2}(3 / 4){ }^{26,27}$ In both types, each $\mathrm{M}^{3+}$ ion $(\mathrm{M}=\mathrm{Sc}$ or $\mathrm{Er})$ has around it six closest oxygen atoms. The presence of inversion symmetry in the $C_{3 \mathrm{i}}$ site is important as it affects the luminescence spectra of the $\mathrm{Sc}_{2} \mathrm{O}_{3}: \mathrm{Er}^{3+}$ nanocrystals. The $f \rightarrow f$ electric dipole transitions are forbidden in the $C_{3 \mathrm{i}}$ site according to the selection rules and as a result, the electric dipole transitions can occur only by weak vibronic coupling. Thus, the spectra presented in this paper are ascribed to emissions from the $\mathrm{Er}^{3+}$ ions in the $C_{2}$ sites with only a minor contribution from $\mathrm{Er}^{3+}$ ions in the $C_{3 \mathrm{i}}$ sites.

The Stokes luminescence spectra of the $\mathrm{Sc}_{2} \mathrm{O}_{3}: \mathrm{Er}^{3+}$ nanocrystal samples under investigation $\left(0.1,1\right.$, and $\left.10 \mathrm{~mol} \% \mathrm{Er}^{3+}\right)$ are presented in Fig. 5 following the direct excitation of the ${ }^{4} \mathrm{~F}_{7 / 2}$ state with $488 \mathrm{~nm}$. A green emission is observed between 515 and $580 \mathrm{~nm}$ and attributed to the ${ }^{2} \mathrm{H}_{11 / 2} \rightarrow{ }^{4} \mathrm{I}_{15 / 2}$ and ${ }^{4} \mathrm{~S}_{3 / 2} \rightarrow{ }^{4} \mathrm{I}_{15 / 2}$ transitions centered at approximately 530 and $560 \mathrm{~nm}$, respectively. A red emission, ascribed to the ${ }^{4} \mathrm{~F}_{9 / 2} \rightarrow{ }^{4} \mathrm{I}_{15 / 2}$ transition, was observed between 640-700 nm. Furthermore, near-infrared (NIR) emission (not shown)

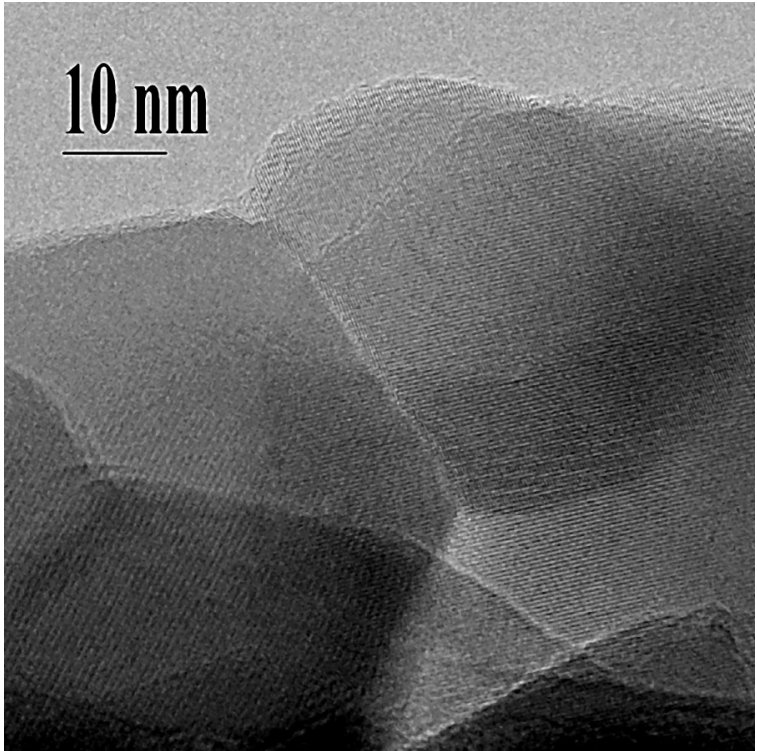

Figure 4. HRTEM micrograph of a typical $\mathrm{Sc}_{2} \mathrm{O}_{3}$ sample.

was observed between 780 and $880 \mathrm{~nm}$ from the ${ }^{4} \mathrm{I}_{9 / 2} \rightarrow{ }^{4} \mathrm{I}_{15 / 2}$ (centered at $800 \mathrm{~nm}$ ) and ${ }^{4} \mathrm{~S}_{3 / 2} \rightarrow{ }^{4} \mathrm{I}_{13 / 2}$ (centered at $860 \mathrm{~nm}$ ) transitions.

Following continuous wave excitation with $980 \mathrm{~nm}$ into the ${ }^{4} \mathrm{I}_{11 / 2}$ intermediate excited state (approximately $10200 \mathrm{~cm}^{-1}$ ), blue, green, and red anti-Stokes emission was observed in all nanocrystalline $\mathrm{Sc}_{2} \mathrm{O}_{3}: \mathrm{Er}^{3+}$ samples under investigation (Fig. 6). A weak anti-Stokes blue emission was observed centered at approximately $495 \mathrm{~nm}$ and occurs via the ${ }^{4} \mathrm{~F}_{7 / 2} \rightarrow{ }^{4} \mathrm{I}_{15 / 2}$ transition. Anti-Stokes emission in the green portion of the electromagnetic spectrum was observed between 515 and $580 \mathrm{~nm}$ and was ascribed to the transi-

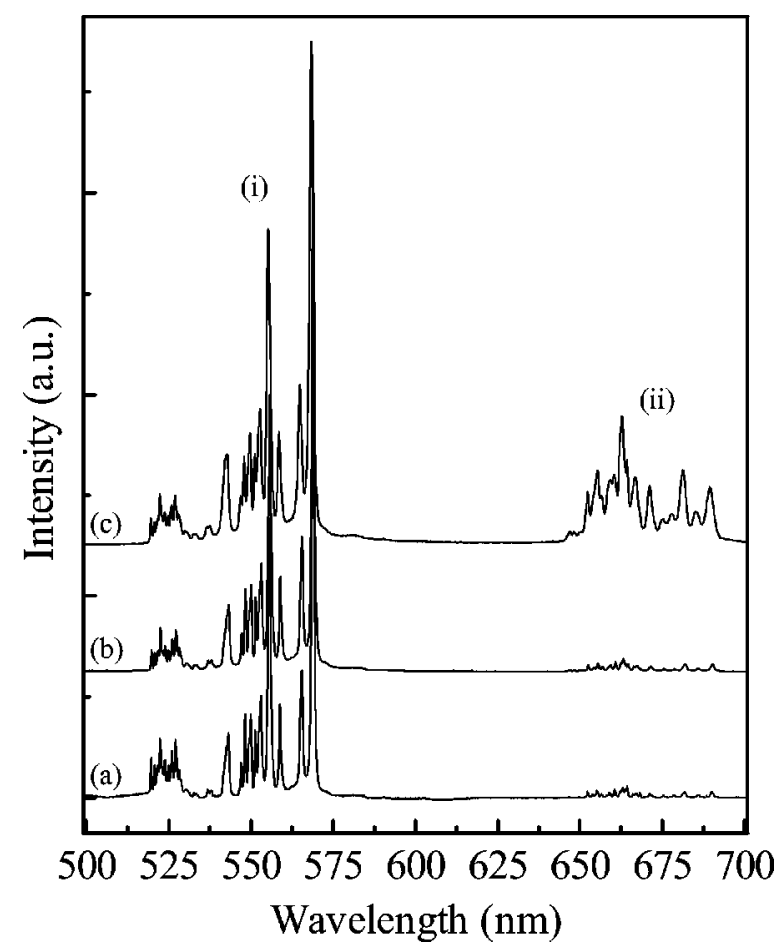

Figure 5. Stokes emission spectra of nanocrystalline $\mathrm{Sc}_{2} \mathrm{O}_{3}$ doped with (a) 0.1 , (b) 1 , and (c) $10 \mathrm{~mol} \% \mathrm{Er}^{3+}$ following excitation with $488 \mathrm{~nm}$. Shown are the (i) ${ }^{2} \mathrm{H}_{11 / 2},{ }^{4} \mathrm{~S}_{3 / 2} \rightarrow{ }^{4} \mathrm{I}_{15 / 2}$; (ii) ${ }^{4} \mathrm{~F}_{9 / 2} \rightarrow{ }^{4} \mathrm{I}_{15 / 2}$ transitions. 


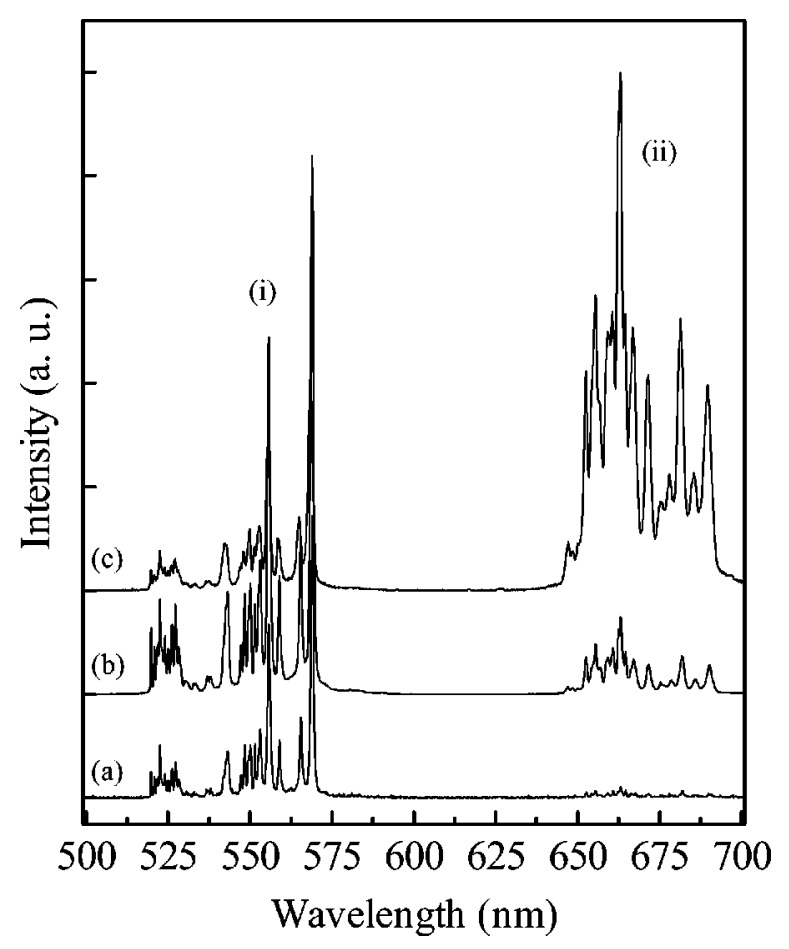

Figure 6. Anti-Stokes emission spectra of nanocrystalline $\mathrm{Sc}_{2} \mathrm{O}_{3}$ doped with (a) 0.1 , (b) 1 , and (c) $10 \mathrm{~mol} \% \mathrm{Er}^{3+}$ following excitation with $980 \mathrm{~nm}$. Shown are the (i) ${ }^{2} \mathrm{H}_{11 / 2},{ }^{4} \mathrm{~S}_{3 / 2} \rightarrow{ }^{4} \mathrm{I}_{15 / 2}$; (ii) ${ }^{4} \mathrm{~F}_{9 / 2} \rightarrow{ }^{4} \mathrm{I}_{15 / 2}$ transitions.

tions from the ${ }^{2} \mathrm{H}_{11 / 2}$ and ${ }^{4} \mathrm{~S}_{3 / 2}$ excited states to the ${ }^{4} \mathrm{I}_{15 / 2}$ ground state and centered at 530 and $560 \mathrm{~nm}$, respectively. Finally, a red anti-Stokes emission was also observed centered at $670 \mathrm{~nm}$ from the ${ }^{4} \mathrm{~F}_{9 / 2} \rightarrow{ }^{4} \mathrm{I}_{15 / 2}$ transition.

To fully elucidate the mechanisms responsible for the anti-Stokes luminescence, a systematic study was undertaken. The first step was to perform an excitation power-dependence study of the antiStokes emission (Fig. 7a). It is well known that the anti-Stokes visible emission intensity $\left(I_{\text {vis }}\right)$ is proportional to the $n$th power of the incident NIR excitation power $\left(I_{\mathrm{NIR}}\right)$. The relation can be written as $^{28}$

$$
I_{\mathrm{vis}} \propto I_{\mathrm{NIR}}^{n}
$$

where $n$ is the number of $980 \mathrm{~nm}$ photons required to populate the emitting excited state. By plotting $\ln \left(I_{\mathrm{vis}}\right) v s . \ln \left(I_{\mathrm{NIR}}\right)$, it is possible to obtain $n$ from the slope of the graph. We determined that $n=2$ for all anti-Stokes transitions in all nanocrystalline samples under investigation (Fig. 7b). Thus, the upper emitting levels are populated via a two-photon upconversion process. There are three well-known mechanisms, which can lead to anti-Stokes emission in lanthanide-doped materials; excited state absorption (ESA), energy transfer upconversion (ETU) and photon avalanche (PA) ${ }^{29-31}$ It is possible to distinguish PA from ESA and ETU by the results of the power study. Photon avalanche requires a certain pump threshold to be met in order for the upconversion to occur with reasonable efficiency and leads to an inflection point in the graph. ${ }^{32}$ Clearly, this was not observed thus ruling out this mechanism (Fig. 7b). In order to discern between the remaining two possible mechanisms (ESA and ETU), we obtained the decay curves following pumping with the upconversion wavelength $\left(\lambda_{\text {exc }}=980 \mathrm{~nm}\right)$ and compared them to the curves acquired following direct excitation of the ${ }^{4} \mathrm{~F}_{7 / 2}$ state with $488 \mathrm{~nm}$ (Table I). These results indicated that the dominant mechanism leading to the anti-Stokes emission is dependent upon the $\mathrm{Er}^{3+}$ dopant concentration. In the $0.1 \mathrm{~mol} \%$ nanocrystalline $\mathrm{Sc}_{2} \mathrm{O}_{3}: \mathrm{Er}^{3+}$ sample, the decay curves at both wavelengths were

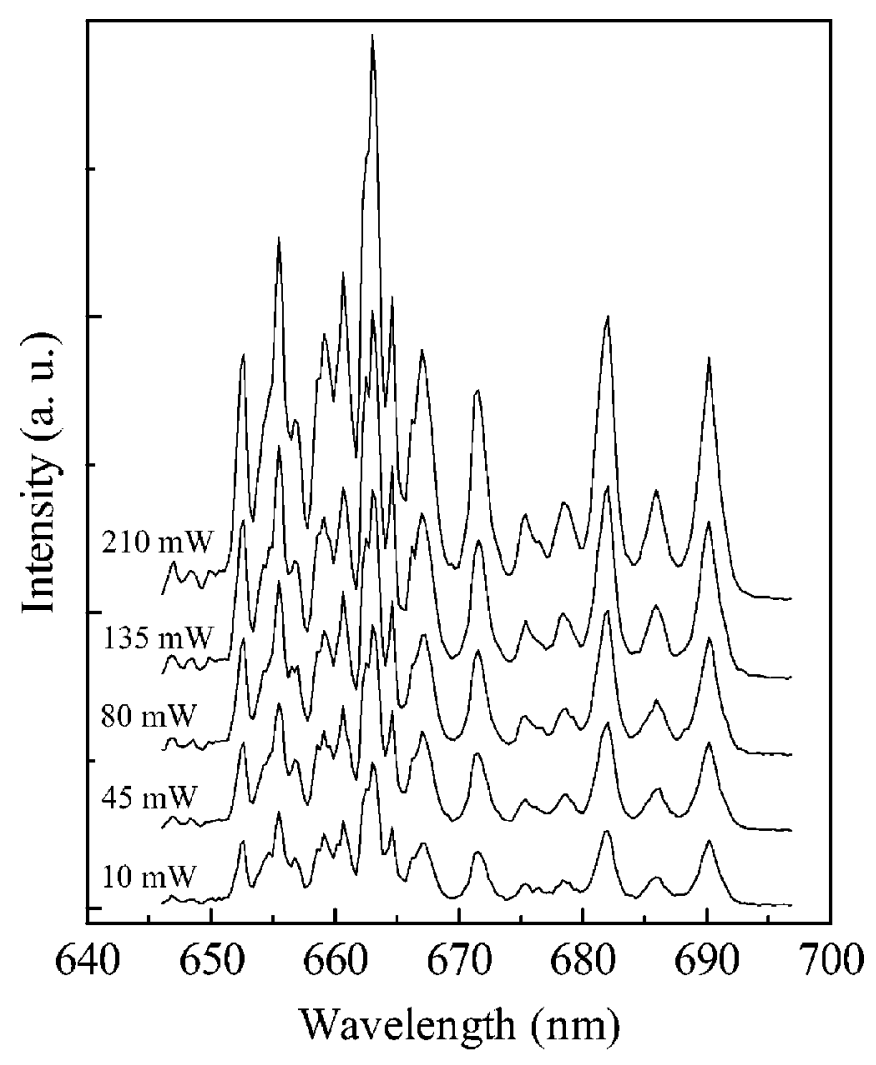

(a)

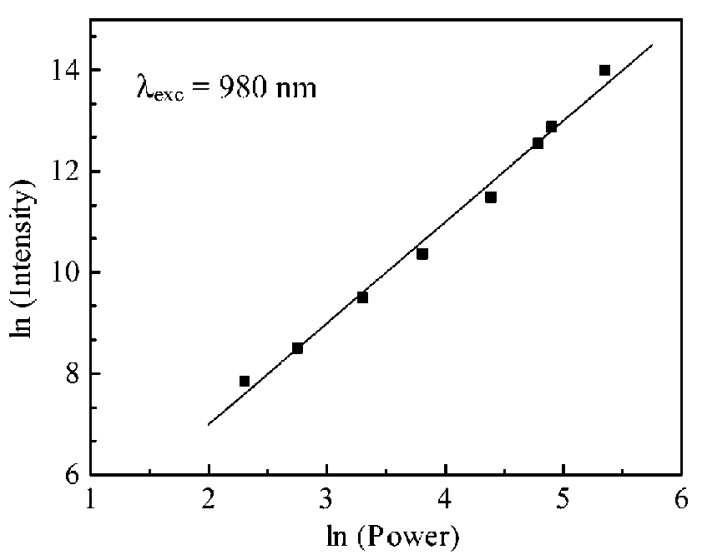

(b)

Figure 7. (a) Power dependence study of the ${ }^{4} \mathrm{~F}_{9 / 2} \rightarrow{ }^{4} \mathrm{I}_{15 / 2}$ anti-Stokes emission following excitation with $980 \mathrm{~nm}$. (b) Graph of $\ln$ (Intensity) vs. In (Power) (slope $n=2$ ).

single exponential and the obtained decay times after excitation with 488 or $980 \mathrm{~nm}$ were identical indicating that the anti-Stokes emission is due only to excited state absorption. The ESA process consists of two sequential excitation steps in a single ion and thus, the decay times are not affected when pumping with an upconversion wavelength. In this mechanism (Fig. 8), the $\mathrm{Er}^{3+}$ ion is excited from the ground state $\left({ }^{4} I_{15 / 2}\right)$ to an intermediate excited state $\left({ }^{4} I_{11 / 2}\right)$ following the absorption of a single $980 \mathrm{~nm}$ photon (ground state absorption, GSA). A second photon is subsequently and immediately absorbed, further exciting the ion from the intermediate excited state (population reservoir) to the upper excited state $\left({ }^{4} \mathrm{~F}_{7 / 2}\right)$. 


\begin{tabular}{|c|c|c|}
\hline \multirow{2}{*}{$\begin{array}{l}\mathrm{Er}^{3+} \text { concentration } \\
(\mathrm{mol} \%)\end{array}$} & \multicolumn{2}{|c|}{ Decay time constant $\left(\tau_{\mathrm{m}}\right)$} \\
\hline & $\lambda_{\mathrm{exc}}=488 \mathrm{~nm}$ & $\lambda_{\mathrm{exc}}=980 \mathrm{~nm}$ \\
\hline 0.1 & 212 & 216 \\
\hline 1 & 98 & 182 \\
\hline 10 & 22 & 92 \\
\hline
\end{tabular}

On the other hand, the decay curves of the 1 and $10 \mathrm{~mol} \%$ nanocrystals demonstrated a deviation from single-exponential behavior principally caused by ion-ion interactions at higher dopant concentrations. Thus, the effective decay time constants, $\tau_{\mathrm{m}}$, were determined by applying the following equation to the experimental decay curves ${ }^{33}$

$$
\tau_{\mathrm{m}}=\frac{\int_{0}^{\infty} t I(t) d t}{\int_{0}^{\infty} I(t) d t}
$$

where $I(t)$ is the intensity at time $t$. The results of the fit are presented in Table I, and it is evident that we observe a lengthening of the decay times following excitation with $980 \mathrm{~nm}$. This lengthening of the anti-Stokes decay times is a clear indication of the presence of energy transfer upconversion. In the ETU process (Fig. 8), an ion excited to its intermediate state (population reservoir, ${ }^{4} \mathrm{I}_{11 / 2}$ ) transfers its energy to a neighboring ion in close proximity, also in its intermediate excited state $\left({ }^{4} \mathrm{I}_{11 / 2}\right)$. This further excites the ion to the upper excited state $\left({ }^{4} \mathrm{~F}_{7 / 2}\right)$ while the initial ion decays nonradiatively to the ground state. In the presence of ETU, the observed decay times can be lengthened as they depend on the lifetime of the excited state from which the energy transfer originates at the donor ion.

The efficiency of this mechanism is strongly dependent on the ion-ion distances and in turn on the concentration of the dopant. Thus, the probability that an $\mathrm{Er}^{3+}$ ion will interact with its neighbor strongly depends on the separation between the two ions. ${ }^{34}$ If the critical distance is achieved, then the probability of the energy transfer is identical to the probability of the internal decay of the isolated donor. The critical distance is dependent upon a variety of factors and for a lanthanide ion is on the order of $10 \AA .{ }^{35}$ As the concentration of the $\mathrm{Ln}^{3+}$ dopant increases, the average distance between ions decreases thus favoring the ETU mechanism. Moreover, the

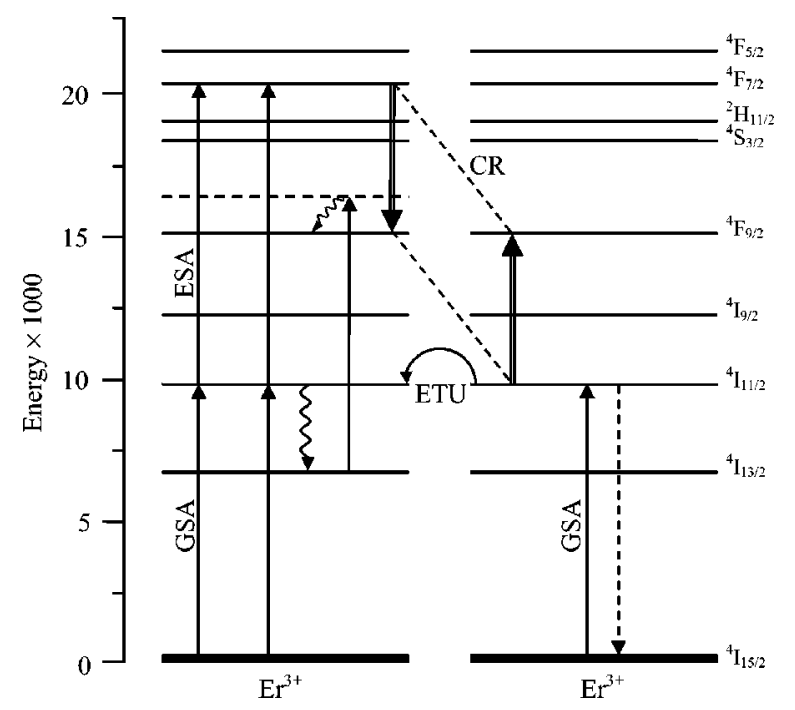

Figure 8. Schematic representation of the different mechanisms responsible for the anti-Stokes emission.
anti-Stokes decay time lengthening is much more drastic in the $10 \mathrm{~mol} \%$ nanocrystals indicating that ETU is the dominant mechanism in this sample. However, in the $1 \mathrm{~mol} \%$ sample, it is most likely that both ESA and ETU are responsible for populating the emitting states.

As the anti-Stokes spectra clearly demonstrate, the red emission $\left({ }^{4} \mathrm{~F}_{9 / 2} \rightarrow{ }^{4} \mathrm{I}_{15 / 2}\right)$ shows an enhancement relative to the green emission $\left({ }^{2} \mathrm{H}_{11 / 2},{ }^{4} \mathrm{~S}_{3 / 2} \rightarrow{ }^{4} \mathrm{I}_{15 / 2}\right)$ as the concentration of $\mathrm{Er}^{3+}$ increases. For example, the anti-Stokes spectrum of the $0.1 \mathrm{~mol} \%$ nanocrystalline $\mathrm{Sc}_{2} \mathrm{O}_{3}: \mathrm{Er}^{3+}$ shows a dominant green emission while in the $10 \mathrm{~mol} \%$ sample, the red emission is most prominent. This enhancement of the red emission has been demonstrated by us previously in isostructural $\mathrm{Y}_{2} \mathrm{O}_{3}: \mathrm{Er}^{3+}$ nanocrystals following excitation with $980 \mathrm{~nm} .{ }^{36,37}$ We proposed two distinct mechanisms, which were directly responsible for populating the ${ }^{4} \mathrm{~F}_{9 / 2}$ and bypassing the green emitting states $\left({ }^{2} \mathrm{H}_{11 / 2}\right.$ and $\left.{ }^{4} \mathrm{~S}_{3 / 2}\right)$. Initially, it was proposed that a cross-relaxation mechanism of the type ${ }^{4} \mathrm{~F}_{7 / 2}+{ }^{4} \mathrm{I}_{11 / 2} \rightarrow{ }^{4} \mathrm{~F}_{9 / 2}$ $+{ }^{4} \mathrm{~F}_{9 / 2}$ could populate the ${ }^{4} \mathrm{~F}_{9 / 2}$ state directly (Fig. 8). In agreement with the experimental data, the efficiency of this process would increase with decreasing the average distance between $\mathrm{Er}^{3+}$ ions and thus with increasing erbium concentration. ${ }^{36} \mathrm{In}_{2} \mathrm{O}_{3}: \mathrm{Er}^{3+}, \mathrm{Yb}^{3+}$ $\left(1 \mathrm{~mol} \%\right.$ each of $\mathrm{Er}^{3+}$ and $\mathrm{Yb}^{3+}$ ) we observed an even stronger enhancement of the red emission compared to the singly doped $\mathrm{Y}_{2} \mathrm{O}_{3}: \mathrm{Er}^{3+}(10 \mathrm{~mol} \%)$ nanocrystals. Furthermore, the red enhancement was much more pronounced in the $\mathrm{Y}_{2} \mathrm{O}_{3}: \mathrm{Er}^{3+}$ nanocrystals compared to the identically doped bulk (microcrystalline) material allowing us to determine that an additional mechanism was active, which utilized the high energy phonons inherently present in the nanocrystalline material. ${ }^{37}$

It is quite feasible that in the singly doped scandia nanocrystalline host, with sufficiently high $\mathrm{Er}^{3+}$ concentration, the following mechanism is also present to directly populate the ${ }^{4} \mathrm{~F}_{9 / 2}$ state (see Fig. 8). The $980 \mathrm{~nm}$ photons will excite two neighboring $\mathrm{Er}^{3+}$ ions to the ${ }^{4} \mathbf{I}_{11 / 2}$ state. Due to the presence of carbonate and hydroxyl ions on the particle surface providing high vibrational energies to the nanocrystalline lattice (1500 and $3350 \mathrm{~cm}^{-1}$, respectively), one of the excited ions will quickly and efficiently decay nonradiatively to the ${ }^{4} \mathrm{I}_{13 / 2}$ state. The neighboring ion (in the ${ }^{4} \mathrm{I}_{11 / 2}$ state) will transfer its energy exciting it to the ${ }^{4} \mathrm{~F}_{9 / 2}$ state. However, there is approximately $1600 \mathrm{~cm}^{-1}$ of excess energy, which is easily dissipated by the nanocrystal lattice to conserve energy. ${ }^{37}$ This mechanism is much less probable in the bulk material as it possesses only the intrinsic phonons of the sesquioxide host (maximum phonon energy about $600 \mathrm{~cm}^{-1}$ ).

However, it should be noted that comparing identically doped $(10 \mathrm{~mol} \%) \mathrm{Y}_{2} \mathrm{O}_{3}: \mathrm{Er}^{3+}$ and $\mathrm{Sc}_{2} \mathrm{O}_{3}: \mathrm{Er}^{3+}$ prepared by the same combustion synthesis, the red enhancement is much more pronounced in the scandia nanocrystals. We attribute this behavior to the difference of the average distances between the $\mathrm{Er}^{3+}$ ions in the host lattice. In fact, the ion distance $d$ in a crystalline host can be estimated using the equation ${ }^{38}$

$$
d=\left(\frac{3}{4 \pi N}\right)^{1 / 3}
$$

where $N$ is the ion density. From the above reported X-ray diffraction (XRD) results, it can be evidenced that the $10 \mathrm{~mol} \% \mathrm{Er}^{3+}$ doped $\mathrm{Sc}_{2} \mathrm{O}_{3}$ under investigation has a unit cell volume $\left(971.95 \AA^{3}\right.$ ) smaller with respect to that of the isostructural $10 \mathrm{~mol} \% \mathrm{Er}^{3+}$ doped $\mathrm{Y}_{2} \mathrm{O}_{3}$ nanocrystalline material ${ }^{25}\left(1193.38 \AA^{3}\right)$. Then, considering the same $10 \mathrm{~mol} \%$ dopant concentration for both sesquioxides, an $\mathrm{Er}^{3+}$ ion average distance of 4.47 and $4.17 \AA$ results for the $10 \mathrm{~mol} \% \mathrm{Er}^{3+}$ doped $\mathrm{Y}_{2} \mathrm{O}_{3}$ and $\mathrm{Sc}_{2} \mathrm{O}_{3}$ nanocrystalline hosts, respectively, using Eq. 3. Therefore, shorter $\mathrm{Er}^{3+}-\mathrm{Er}^{3+}$ distances will result in $\mathrm{Sc}_{2} \mathrm{O}_{3}$ compared to $\mathrm{Y}_{2} \mathrm{O}_{3}$. The shorter ion-ion distances will result in a much higher transfer probability between the $\mathrm{Er}^{3+}$ ions, which is dependent upon the sixth power of the inverse of 
the dopant distance (for dipole-dipole interactions), ${ }^{39}$ and consequently, the red enhancement will be greater in $\mathrm{Sc}_{2} \mathrm{O}_{3}: \mathrm{Er}^{3+}$ as both mechanisms responsible for populating the ${ }^{4} \mathrm{~F}_{9 / 2}$ state will be more efficient.

In order to fully understand the anti-Stokes red enhancement, a thorough study is required by investigating the effect of the ionic radius of the host dopant in sesquioxide nanocrystals. Studies are currently under way to compare the enhancement of the red anti-Stokes emission in cubic $\mathrm{Y}_{2} \mathrm{O}_{3}: \mathrm{Er}^{3+}, \mathrm{Lu}_{2} \mathrm{O}_{3}: \mathrm{Er}^{3+}$, and $\mathrm{Sc}_{2} \mathrm{O}_{3}: \mathrm{Er}^{3+}$ nanocrystals.

\section{Conclusions}

Confirmed by XRD results, samples of undoped and $\mathrm{Er}^{3+}$ doped nanocrystalline $\mathrm{Sc}_{2} \mathrm{O}_{3}$ were obtained, with a crystallite average dimension of 37 and $27 \mathrm{~nm}$, respectively. TEM micrographs showed that the samples are composed of interconnected crystalline particles with irregular, sharp-edged shapes. The luminescence properties of the $\mathrm{Sc}_{2} \mathrm{O}_{3}$ nanocrystals doped with $0.1,1$, and $10 \mathrm{~mol} \% \mathrm{Er}^{3+}$ were investigated. Green $\left({ }^{2} \mathrm{H}_{11 / 2},{ }^{4} \mathrm{~S}_{3 / 2} \rightarrow{ }^{4} \mathrm{I}_{15 / 2}\right)$, red $\left({ }^{4} \mathrm{~F}_{9 / 2} \rightarrow{ }^{4} \mathrm{I}_{15 / 2}\right)$, and NIR $\left({ }^{4} \mathrm{I}_{9 / 2} \rightarrow{ }^{4} \mathrm{I}_{15 / 2}\right.$ and $\left.{ }^{4} \mathrm{~S}_{3 / 2} \rightarrow{ }^{4} \mathrm{I}_{13 / 2}\right)$ Stokes emission was observed from the $\mathrm{Er}^{3+}$ ion following excitation with $488 \mathrm{~nm}$. The anti-Stokes emission $\left(\lambda_{\text {exc }}=980 \mathrm{~nm}\right)$ was studied, and it was determined that the mechanism responsible for populating the emitting states was dependent upon the concentration of the dopant ion. In $0.1 \mathrm{~mol} \% \mathrm{Sc}_{2} \mathrm{O}_{3}: \mathrm{Er}^{3+}$ nanocrystals, upconversion was determined to occur via excited state absorption (ESA) since the decay time of the ${ }^{4} \mathrm{~S}_{3 / 2}$ state obtained when directly populating the ${ }^{4} \mathrm{~F}_{7 / 2}$ excited state with $488 \mathrm{~nm}$ was identical to that obtained when utilizing 980 $\mathrm{nm}$ as the pump wavelength. On the other hand, the 1 and $10 \mathrm{~mol} \%$ samples showed a lengthening of the decay times obtained with 980 $\mathrm{nm}$ confirming the presence of energy transfer upconversion (ETU).

A concentration-dependent enhancement of the red emission $\left({ }^{4} \mathrm{~F}_{9 / 2} \rightarrow{ }^{4} \mathrm{I}_{15 / 2}\right)$ was observed in the anti-Stokes emission spectra following excitation with $980 \mathrm{~nm}$. A cross-relaxation mechanism of the type ${ }^{4} \mathrm{~F}_{7 / 2}+{ }^{4} \mathrm{I}_{11 / 2} \rightarrow{ }^{4} \mathrm{~F}_{9 / 2}+{ }^{4} \mathrm{~F}_{9 / 2}$ was in part responsible for directly populating the ${ }^{4} \mathrm{~F}_{9 / 2}$ state and bypassing the green emitting states $\left({ }^{2} \mathrm{H}_{11 / 2}\right.$ and $\left.{ }^{4} \mathrm{~S}_{3 / 2}\right)$. Also, following excitation of the ion to the ${ }^{4} \mathrm{I}_{11 / 2}$ state $\left(\lambda_{\text {exc }}=980 \mathrm{~nm}\right)$ the large vibrational energies of the carbonate and hydroxyl ions impurities present in these nanocrystalline materials, induce efficient multiphonon decay to the ${ }^{4} \mathrm{I}_{13 / 2}$ state. The resulting nonresonant ${ }^{4} \mathrm{~F}_{9 / 2} \leftarrow{ }^{4} \mathrm{I}_{13 / 2}$ transition was also responsible for the direct population of the ${ }^{4} \mathrm{~F}_{9 / 2}$ level with the excess energy easily dissipated by the $\mathrm{Sc}_{2} \mathrm{O}_{3}$ lattice. Furthermore, the enhancement of the red emission was more prominent in $\mathrm{Sc}_{2} \mathrm{O}_{3}: \mathrm{Er}^{3+}$ nanocrystals compared to identically doped $\mathrm{Y}_{2} \mathrm{O}_{3}: \mathrm{Er}^{3+}$. This was caused by the shorter $\mathrm{Er}^{3+}-\mathrm{Er}^{3+}$ distances in the $\mathrm{Sc}_{2} \mathrm{O}_{3}: \mathrm{Er}^{3+}$ nanocrystals due to the lower unit cell volume $\left(971.95 \AA^{3}\right.$ ) compared to that of $\mathrm{Y}_{2} \mathrm{O}_{3}: \mathrm{Er}^{3+}$ nanocrystals $\left(1193.38 \AA^{3}\right)$.

\section{Acknowledgments}

The authors gratefully thank Erica Viviani (Università di Verona, Italy) for expert technical assistance and T. Finotto (Università di Venezia, Italy) for the X-ray diffraction experimental work. The authors acknowledge the Natural Science and Engineering Research Council of Canada and MIUR of Italy (project 2003035190), for financial support.
Concordia University assisted in meeting the publication costs of this article.

\section{References}

1. Y. Tao, G. Zhao, W. Zhang, and S. Xia, Mater. Res. Bull., 32, 501 (1997).

2. G. Tessari, M. Bettinelli, A. Speghini, D. Ajò, G. Pozza, L. E. Depero, B. Allieri, and L. Sangaletti, Appl. Surf. Sci., 144-145, 686 (1999).

3. L. E. Shea, J. McKittrick, and O. A. Lopez, J. Am. Ceram. Soc., 79, 3257 (1996).

4. X. Yu, P. Xie, and Q. Su, Phys. Chem. Chem. Phys., 3, 5266 (2001).

5. G. A. Hirata, F. Ramos, R. Garcia, E. J. Bosze, J. McKittrick, O. Contreras, and F. A. Ponce, Phys. Status Solidi A, 188, 179 (2001).

6. A. I. Ekimov and A. A. Onushchenko, Fiz. Tekh. Poluprovodn. (S.-Peterburg), 16, 1215 (1982).

7. R. Rosseti, S. Nakahara, and L. E. Brus, J. Chem. Phys., 79, 1086 (1983).

8. R. Rosseti, J. L. Ellison, J. M. Gibson, and L. E. Brus, J. Chem. Phys., 80, 4464 (1984).

9. A. P. Alivisatos, J. Phys. Chem., 100, 13226 (1996).

10. A. Konrad, U. Herr, R. Tidecks, F. Kummer, and K. Samwer, J. Appl. Phys., 90 $3516(2001)$.

11. J. A. Capobianco, F. Vetrone, J. C. Boyer, A. Speghini, and M. Bettinelli, J. Phys. Chem. B, 106, 1181 (2002).

12. L. Fornasiero, E. Mix, V. Peters, K. Petermann, and G. Huber, Ceram. Int., 26, 589 (2000).

13. E. Antic-Fidancev, J. Hölsa, and M. Lastusaari, J. Phys.: Condens. Matter, 15, 863 (2003).

14. D. Grosso and P. A. Sermon, J. Mater. Chem., 10, 359 (2000).

15. C. N. J. Wagner, in Local Atomic Arrangements Studied by X-Ray Diffraction, J. B. Cohen and J. E. Hilliard, Editors, Metallurgical Society Conferences, p. 219, Gordon \& Breach, New York (1966)

16. R. P. I. Adler and C. N. J. Wagner, J. Appl. Phys., 33, 3451 (1962).

17. S. Enzo, S. Polizzi, and A. Z. Benedetti, Z. Kristallogr, 170, 275 (1985).

18. A. Benedetti, G. Fagherazzi, S. Enzo, and M. Battagliarin, J. Appl. Crystallogr, 21 543 (1988).

19. B. E. Warren and B. L. Averbach, J. Appl. Phys., 21, 595 (1950).

20. B. E. Warren and B. L. Averbach, J. Appl. Phys., 23, 497 (1952).

21. Powder Diffraction File, JCPDS International Center for Diffraction Data, Swarthmore, PA, PDF n.42-1463.

22. Handbook of Physics and Chemistry, 78th ed., D. R. Lide, Editor, p. 4-121, CRC Press, Boca Raton, FL (1998)

23. S. Polizzi, S. Bucella, A. Speghini, F. Vetrone, R. Naccache, J. C. Boyer, and J. A. Capobianco, Chem. Mater, 16, 1330 (2004).

24. G. Fagherazzi, S. Polizzi, M. Bettinelli, and A. Speghini, J. Mater. Res., 15, 586 (2000)

25. S. Polizzi, G. Fagherazzi, M. Battagliarin, M. Bettinelli, and A. Speghini, J. Mater Res., 16, 146 (2001).

26. K. Petermann, G. Huber, L. Fornasiero, S. Kuch, E. Mix, V. Peters, and S. A. Basun, J. Lumin., 87-89, 973 (2000).

27. E. Antic-Fidancev, J. Hölsa, and M. Lastusaari, J. Alloys Compd., 341, 82 (2002)

28. M. A. Chamarro and R. Cases, J. Lumin., 46, 59 (1990).

29. N. Bloembergen, Phys. Rev. Lett., 2, 84 (1959).

30. F. Auzel, C. R. Acad. Sci. (Paris), 262, 1016 (1966).

31. J. S. Chivian, W. E. Case, and D. D. Eden, Appl. Phys. Lett., 35, 124 (1979).

32. M. F. Joubert, Opt. Mater. (Amsterdam, Neth.), 11, 181 (1999).

33. E. Nakazawa, in Phosphor Handbook, S. Shionoya and W. M. Yen, Editors, p. 101, CRC Press, Boca Raton, FL (1999).

34. J. Wang and D. J. Simkin, Phys. Rev. B, 52, 3309 (1995).

35. S. V. Sergeyev and B. Jaskorzynska, Phys. Rev. B, 62, 15628 (2000).

36. F. Vetrone, J. C. Boyer, J. A. Capobianco, A. Speghini, and M. Bettinelli, Chem Mater, 15, 2737 (2003).

37. F. Vetrone, J. C. Boyer, J. A. Capobianco, A. Speghini, and M. Bettinelli, J. Phys. Chem. B, 107, 1107 (2003)

38. D. F. de Sousa, F. Batalioto, M. J. V. Bell, S. L. Oliveira, and L. A. O. Nunes, $J$. Appl. Phys., 90, 3308 (2001)

39. F. Auzel, Chem. Rev. (Washington, D.C.), 104, 139 (2004). 